\title{
Endometrite fúngica em éguas: diagnóstico e implicações clínico-patológicas*
}

\section{Fungal endometritis in mares: diagnosis and clinicopathological aspects}

\author{
José Antônio Ribas, ${ }^{* *}$ Eulógio Queiroz Carvalho, ${ }^{* * *}$ Jussara Pedroso Stussii***
}

\begin{abstract}
Resumo
Este estudo objetivou estabelecer a etiologia e achados clínico-patológicos das endometrites fúngicas. Para tal, realizou-se anamnese, exame ginecológico, cultura, citologia e biópsia endometriais em 85 éguas em idade reprodutiva e que não pariam havia um ano ou mais. Das 85 éguas, 24 (28\%) apresentaram exames compatíveis com endometrite infecciosa. Destas, em $20 \%$ (5/24), confirmou-se endometrite com envolvimento fúngico. Os fungos isolados foram: Candida guilliermondii, C. tropicalis, C. pseudotropicalis associadas ao Bacillus sp. em uma égua; C. albicans em duas fêmeas (uma associada a Escherichia coli); um caso de Trichosporon penicillatum e um de T. capitatum. Todos animais diagnosticados com endometrite fúngica apresentaram inflamações endometriais moderadas, nos exames de citologia e no histopatológico, sendo estes achados compatíveis com o histórico e o exame reprodutivo destes animais. Destacou-se a presença constante de linfócitos e plasmócitos nos dois exames, assim como das lesões degenerativas no endométrio através da biópsia endometrial. Em $80 \%(4 / 5)$ constataram-se estruturas fúngicas na citologia endometrial, porém no exame histopatológico, não foi possível detectar tais estruturas. Após o estudo pode-se afirmar que a metodologia utilizada foi eficiente para diagnosticar a endometrite fúngica, com destaque para o exame de citologia endometrial, e que este tipo de endometrite teve caráter crônico em todos os animais.
\end{abstract}

Palavras-chave: biópsia endometrial, citologia endometrial, enfermidade uterina, égua.

\begin{abstract}
The aim of the present study was to determine the causes and clinical findings of endometritis. The history, reproductive examination and endometrials culture, uterine cytology and biopsy from 85 mares in reproductive age that did not foal a year or more were performed. Twenty four (28\%) out of 85 mares had signals compatible with infectious endometritis. From those, 20\% (5/24) had fungal involvement, and the agents were: Candida guilliermondii, C. tropicalis, C. pseudotropicalis, in association to Bacillus $\mathrm{sp}$. in one mare; two mares had C. albicans, and one of them associated with Escherichia coli; a case of Trichosporon penicillatum and another of $T$. capitatum. All animals with fungal endometritis presented moderate endometrial inflammation, at cytology and uterine biopsy, which was compatible with the animal's history and reproductive exam. The endometrial cytology and biopsy revealed numerous lymphocytes and plasmocytes as well as the degenerative lesions in the endometrial biopsy. Fungal structures were presented at the endometrial cytology smears in $80 \%(4 / 5)$ of the mares, however those structures were not detected in the biopsy. In conclusion, the methodology used was efficient to diagnose fungal endometritis, with standing for the examination of endometrial cytology, and the fungal endometritis had chronic character in all animals.
\end{abstract}

Keywords: endometrial biopsy, endometrial cytology, uterus disease, mare.

\section{Introdução}

As endometrites são alterações inflamatórias agudas ou degenerativas do endométrio, as quais podem, ou não, estar associadas à presença de agentes infecciosos (Mattos et al., 2003). A endometrite é a terceira enfermidade de maior ocorrência em equinos (Card, 2005), levando a consideráveis perdas econômicas para a equideocultura (Blanchard et al., 1998).

Na maioria das vezes, a endometrite infecciosa apresenta origem bacteriana (Riddle et al., 2007), todavia, fungos leveduriformes e menos frequentemente filamentosos, são potencialmente patogênicos para o endométrio das éguas (GhasemzadehNava et al, 2004; LeBlanc, 2008). Os fungos mais comumente isolados nas endometrites são Candida spp. (Abou-Gabal et al., 1977; Frontoso et al., 2008), principalmente a Candida albicans (Dascanio et al., 2001; Amaral et al., 2007), porém fungos filamentosos dos gêneros Aspergillus, Penicillium, Mucor e Trichosporon também podem estar relacionados (Blue, 1983; Albihin et al., 2003; Amaral et al., 2007). Como as bactérias que ocasionam as endometrites são essencialmente contaminantes e oportunistas, infecções mistas entre fungos e bactérias podem ocorrer (LeBlanc et al., 2007; Frontoso et al., 2008).

\footnotetext{
${ }^{*}$ Recebido em 20 de março de 2014 e aceito em 13 de setembro de 2014.

${ }^{* *}$ Professor do Departamento de Fisiologia e Farmacologia- Universidade Federal Fluminense. E-mail para contato: ribasjas@vm.uff.br.

*** Professor da Universidade Estadual do Norte Fluminense - CCTA, Laboratório de Sanidade Animal.

${ }^{* * * *}$ Professora do Departamento de Microbiologia e Parasitologia - Universidade Federal Fluminense.
} 
A maioria das endometrites fúngicas tem caráter crônico, sendo diagnosticadas em éguas susceptíveis a endometrites persistentes, ou seja, naquelas que apresentam falhas físicas, imunológicas ou linfáticas nos mecanismos de defesa uterina (Fumuso et al., 2007; Bucca et al., 2008). Porém, casos agudos podem acontecer principalmente após abortos com etiologia micótica (Langoni, 1995; Petrites-Murphy et al., 1996).

Nas últimas décadas houve um aumento dos casos de endometrites fúngicas (Liu e Troedsson, 2008; Ferris et al., 2013). Este fato pode ser atribuído à maior exposição das éguas a fatores facilitadores ou predisponentes para a colonização fúngica como: tratamentos intrauterinos com antibióticos (Carter e Chengappa, 1995; Alvarenga, 2008), frequente manipulação genital e administração prolongada de progesterona e/ou hormônios corticoides, como ocorre nas fêmeas em programas de transferência de embriões, enfermidades cervicais e autocontaminação fecal devido à má-conformação vulvar (Hinrichs et al., 1992; Nico et al., 1994; LeBlanc, 2008; Liu e Troedsson, 2008). A maior conscientização sobre sua ocorrência e a busca por metodologias mais específicas para seu diagnóstico também podem ter contribuído para o aumento dos casos relatados na literatura científica (Ferris et al., 2013).

No entanto, ainda encontram-se dificuldades em fazer um diagnóstico preciso da endometrite fúngica. Vários fatores contribuem para isso, como a falta de direcionamento de material uterino para a cultura fúngica em meios específicos, demora no crescimento das colônias fúngicas, necessidade de colorações especiais que facilitam a visualização do fungo na amostra de tecido (Amaral et al., 2007; Alvarenga, 2008).

Considerando a relevância da endometrite como principal causa de infertilidade em éguas e que os fungos são agentes etiológicos capazes de causá-la, o presente estudo objetivou verificar se as metodologias utilizadas estão adequadas ao diagnóstico de endometrite fúngica, relacionar os principais fungos causadores desta endometrite e descrever os principais achados clínico-patológicos das éguas acometidas por esta patologia.

\section{Material e métodos}

Oitenta e cinco éguas em idade reprodutiva (3- 24 anos, média de 14,5 anos e meio), das raças Campolina, Mangalarga e Mangalarga Marchador, procedentes de várias regiões do Estado do Rio de Janeiro e que não pariam havia um ano ou mais, foram clinicamente examinadas. Durante a obtenção do histórico, procurou-se identificar indícios de susceptibilidade a endometrites persistentes sendo considerados como "positivos" (+) os seguintes fatores: idade avançada, número de parições, endometrites anteriores, tratamentos realizados, ciclos irregulares, partos distócicos, retenção de placenta, abortamentos e perdas embrionárias, dois ou mais insucessos na coleta de embriões. Na ausência de indícios no histórico e na anamnese foram considerados negativos (-) para susceptibilidade a endometrite. O manejo reprodutivo empregado na propriedade, o nível nutricional dos animais, o aspecto sanitário e a frequência de supervisão veterinária na propriedade, também foram anotados nas fichas individuais de cada animal.

O exame ginecológico foi realizado sempre nos cinco primeiros dias do diestro, para melhor padronização e comparação dos achados clínicos e laboratoriais, uma vez que se preconiza a coleta da biópsia neste período (Kenney e Doig, 1986). Inspecionou-se a cauda, vulva e períneo, a fim de verificar lesões nesta região. A conformação vulvar foi avaliada, realizandose o "Índice de Caslick" (IC) (Ley, 2001). Para realizar-se o exame de palpação transretal, a cauda da égua foi envolta em atadura e logo após, avaliou-se a cérvix, o útero e os ovários, quanto ao tamanho, simetria, conteúdo, consistência e a tubularidade do útero e cérvix seguindo-se o proposto por Blanchad et al. (1998). Realizou-se, então, a limpeza perineal com antisséptico Killol $\circledast$ (Quinabra, Química Natural Brasileira Ltda, São José dos Campos, SP, Brasil) a $10 \%$ secando-se após 10 minutos com papel-toalha. Um espéculo estéril e umedecido com solução fisiológica foi introduzido na vagina para se realizar o exame de vaginoscopia como indicado por Speirs (1999). O exame ginecológico foi considerado positivo (+) para endometrite, quando se observaram alterações como: presença de exsudatos e secreções no útero, cérvix e vagina; atrofia das pregas endometriais; alteração do tônus uterino; anormalidades de cérvix, principalmente fibroses e aderências; lacerações; acúmulos de ar e urina; alterações na conformação da vagina e vulva entre outros e negativo (-) quando estas não eram observadas.

Após o exame de vaginoscopia, colheu-se material para a execução dos exames de complementação diagnóstica, sendo feito na seguinte ordem: $\left(1^{\circ}\right)$ swab para cultura, $\left(2^{\circ}\right)$ swab para a confecção do citológico endometrial, $\left(3^{\circ}\right)$ biópsia endometrial para exame histopatológico.

Com o intuito de reduzir os riscos de contaminação, optou-se por swabs protegidos, procedendo-se à colheita tanto para realização da cultura, quanto para a citologia endometrial segundo Card (2005), introduzindo-se o swab na palma da mão enluvada e só expondo-o após a sua passagem pela cérvix.

Após a colheita, o swab para a cultura foi transportado sob refrigeração até o laboratório e o material semeado em duas placas de ágar Sabouraud com cloranfenicol a $10 \%$, duas com ágar seletivo para fungos patogênicos (cloranfenicol e cicloheximida). Incubaram-se as placas à temperatura ambiente $\left(25^{\circ} \mathrm{C}\right)$, por até 15 dias, inspecionando-se diariamente o crescimento fúngico. Após o desenvolvimento de Unidades Formadoras de Colônias (UFC) foi realizada a identificação do fungo. Para fungos filamentosos artrosporados e leveduras realizaram-se a semeadura em profundidade e provas de fermentação (glicose, galactose, sacarose, maltose e lactose) e assimilação de carboidratos (glicose, galactose, sacarose, maltose, lactose, rafinose, trealose, melibiose, celobiose, xilose, ramanose e sorbose), e assimilação de fontes nitrogenadas (peptona e $\mathrm{KNO}_{3}$ ), sendo a identificação da espécie realizada como descrito por McGinnis (1980). A prova de formação do tubo germinativo em meio de leite foi utilizada para a identificação da Candida. albicans (Jitsurong et al., 1993).

Já para fungos filamentosos e esporulados, utilizou-se o preconizado por Looder e Van Rij (1970): microcultivo, confecção de lâminas com lactofenol-azul de algodão para identificação do gênero do fungo através de suas características morfológicas e da espécie por provas específicas, dependendo do gênero.

Para efeito de complementação diagnóstica, o material colhido também foi semeado em caldo cérebro coração $(\mathrm{BHI})$ para que se procedesse ao isolamento e a identificação das bactérias, 
sendo este material após a semeadura, incubado a $37^{\circ} \mathrm{C}$ por 18-24 horas. Os espécimes foram posteriormente inoculados nos meios de cultura ágar sangue (AS), ágar manitol salgado (MS) e ágar Teague-EMB e mantidos sob as mesmas condições de incubação. A partir do crescimento bacteriano procedeu-se à identificação das espécies, segundo Murray et al. (1999).

Quando houve crescimento de pelo menos um micro-organismo a cultura endometrial foi considerada positiva (+) e quando não havia crescimento, foi considerada negativa (-).

Para a citologia endometrial foram feitos dois esfregaços em lâminas, fixados em álcool comum e corados pela técnica de Papanicolau (Jimenes e Ortiz, 1978). A análise foi realizada em microscópio óptico, com óleo de imersão e objetiva de 100x, como proposto por Riddle et al. (2007). Foram avaliados, no mínimo, 10 campos e classificou-se a inflamação em ausente (-) quando foram encontradas células endometriais e menos de 2 neutrófilos/campo na amostra e presente (+) quando foram observados 2 - 5 neutrófilos/por campo (inflamação moderada) ou mais que 5 neutrófilos/campo (inflamação severa). Pesquisaram-se ainda outras células inflamatórias (eosinófilos, macrófagos, hemosiderófagos, linfócitos/plasmócitos), assim como hemácias (Dascanio et al., 2007), muco (Causey, 2007) e estruturas fúngicas: células leveduriformes hifas e pseudo-hifas (Alvarenga, 2008).

A colheita e processamento do fragmento da biópsia endometrial foram realizados como preconizado por Kenney (1978), com auxílio da pinça de Yeoman, tipo "boca de jacaré" (Botupharma Ind. e Com. de Prod. Veterinários Ltda., Botucatu, SP, Brasil), $\mathrm{O}$ fragmento do tecido endometrial de aproximadamente $2 \mathrm{~cm}$, foi retirado da junção do corpo com o corno uterino direito, e então imerso em Bouin por 24 horas. Posteriormente o fragmento foi processado, incluído em parafina histológica e corado pela Hematoxilina-Eosina (HE). Após a análise das lâminas da biópsia endometrial, classificaram-se as éguas em quatro categorias, I, IIA, IIB, III, dependendo das alterações observadas, como proposto por Kenney e Doig (1986). Foram ainda avaliadas quanto à presença $(+)$ ou ausência $(-)$ de infiltrado inflamatório. Avaliações relativas às alterações degenerativas do endométrio, principalmente fibroses periglandulares e vasculares e ninhos endometriais fibrosados, foram realizadas conforme proposto por Hoffman et al. (2009). Foram consideradas positivas (+) quando presentes e negativas (-) quando ausentes. Para melhor demonstração histológica de estruturas fúngicas, foram utilizadas amostras de cortes histológicos corados pela técnica de "Gomori metenamina-prata" (GMS), como descrito por Culling et al. (1985). Se presentes, o exame foi considerado positivo (+) e se ausentes, negativo (-).

Foram consideradas endometrites infecciosas aquelas em que se observaram indícios condizentes $(+)$ com endometrites no histórico e anamnese e/ou exame ginecológico, acompanhados de cultura positiva (+) e reação inflamatória (+) confirmada pelos exames citológico e/ou histopatológico endometrial (Nielsen, 2005; Fumuso et al., 2007). Quando o patógeno isolado na cultura era um fungo ou quando foram identificadas estruturas fúngicas nos exames complementares de diagnóstico considerou-se a endometrite como fúngica (Pugh et al., $1986^{\mathrm{a}-\mathrm{b}}$ ).

Os resultados são apresentados de acordo com a distribuição de frequência (\%), dos eventos estudados para facilitar a comparação com outras pesquisas.

\section{Resultados e discussão}

No presente estudo constatou-se que 28,2\% (24/85) das éguas (Tabela 1) que não pariam havia um ano ou mais, apresentavam endometrite infecciosa, ou seja, com envolvimento de bactérias e/ou fungos, corroborando com os relatos de LeBlanc et al. (2007), que afirmam que esta patologia ocorre em $25-60 \%$ das éguas vazias.

Para evitar um falso diagnóstico de endometrite infecciosa foi necessário associar as informações colhidas sobre a vida reprodutiva deste animal aos vários exames realizados (Tabela 1), o que está de acordo com estudos anteriores (Jacob et al., 2002, Fumuso et al., 2007; LeBlanc et al., 2007; Bucca et al., 2008). É válido ressaltar que a identificação destas éguas é muito importante (Malschitzky et al., 2007), uma vez que elas dependem de tratamento para voltar a gestar. Avaliando-se os históricos e as anamneses das éguas, constataram-se sinais de endometrite nas 24 éguas (100\%) diagnosticadas como positivas para endometrite infecciosa (bacteriana e/ou fúngicas).

Procedendo-se da mesma forma para com o exame ginecológico, observou-se que 22 éguas (91,7\%) apresentavam exame(s) sugestivo(s) de endometrite (Tabela 1).

Das 85 éguas do estudo, cinco (5,9\%) apresentaram endometrite fúngica (éguas, 1, 6, 10, 22 e 23, Tabelas 1 e 2), sendo o agente etiológico encontrado em $20,8 \%$ das éguas com endometrites consideradas como infecciosas. Os dados encontrados na literatura para endometrite com etiologia fúngica variam entre 2,0 e 13,5\% (Collins, 1964; Bain, 1966; Pugh et al., 1986a; Langoni et al., 1999; Dascanio et al., 2001; Amaral et al., 2007; LeBlanc et al., 2007; Riddle et al., 2007; Frontoso et al., 2008), porém a comparação entre os resultados fica bastante difícil devido à grande variação utilizada na escolha dos animais em que foi realizado o diagnóstico da infecção fúngica.

Amaral et al. (2007) também constataram índices elevados de endometrite fúngica $(13,5 \%)$ em sua pesquisa realizada no Brasil. Este fato talvez indique que as endometrites causadas por fungos sejam mais comuns em regiões tropicais, devido ao ambiente ser mais propenso ao desenvolvimento do fungo durante todo o ano como relatam Lacaz et al. (1984), expondo continuamente os animais a um grande número de esporos, fato apontado por Carter e Chenpaga (1995) como um importante fator predisponente para a endometrite micótica. Porém, como existem poucas pesquisas relativas a este tipo de endometrites nas regiões tropicais, por enquanto não se pode confirmar tal fato.

Provavelmente o maior número de confirmações de endometrites fúngicas neste estudo se deva à utilização de meios específicos, além de temperatura e tempo de cultivo adequados para estes micro-organismos. Muitas endometrites fúngicas não são diagnosticadas devido a não se proceder corretamente à cultura e ao isolamento do fungo (Amaral et al., 2007). Devem-se utilizar meios específicos para o crescimento fúngico (com antibióticos), pois estes suprimem o crescimento de bactérias, que poderiam tomar toda a placa de cultura antes que o fungo tivesse chance de formar colônias. Além disso, esta deve ser realizada a temperatura ambiente $\left(25^{\circ} \mathrm{C}\right)$, já que a temperatura elevada é um fator limitante do crescimento fúngico (Aboud-Gabal et al., 1977; Pugh et al., 1986 $\left.{ }^{a-b}\right)$. Também não se deve descartar a cultura do fungo antes de 15 dias, uma vez que o fungo tem crescimento lento (Freeman et al., 1986; Amaral et al., 2007). 
Tabela 1: Raça, idade, classificação da biópsia endometrial (H.E.) e positividade para endometrite do histórico, anamnese e exames ginecológico, cultura endometrial, citologia endometrial, biópsia- infiltrado inflamatório, biópsia- alterações degenerativas e biópsia (G.M.S.) das 24 éguas

\begin{tabular}{|c|c|c|c|c|c|c|c|c|c|c|}
\hline Égua no & Raça & Idade & $\begin{array}{l}\text { Histórico/ } \\
\text { anamnese }\end{array}$ & $\begin{array}{c}\text { Exame } \\
\text { ginecológico }\end{array}$ & $\begin{array}{c}\text { Cultura } \\
\text { endometrial }\end{array}$ & $\begin{array}{l}\text { Citologia } \\
\text { endometrial }\end{array}$ & $\begin{array}{l}\text { Biópsia } \\
(\text { H.E. })^{\text {a }}\end{array}$ & $\begin{array}{c}\text { Biópsia } \\
\text { infiltrado } \\
\text { inflamatório }\end{array}$ & $\begin{array}{c}\text { Biópsia } \\
\text { alterações de- } \\
\text { generativas }^{\mathrm{b}}\end{array}$ & $\begin{array}{l}\text { Biópsia } \\
\text { (GMS) }^{c}\end{array}$ \\
\hline 1 & $\mathrm{MA}$ & 15 & + & + & + & + & $\mathrm{II}_{\mathrm{B}}$ & + & + & - \\
\hline 2 & MA & 13 & + & + & + & + & $\mathrm{II}_{\mathrm{B}}$ & - & + & - \\
\hline 3 & MA & 15 & + & + & + & + & $\mathrm{I}_{\mathrm{B}}$ & + & + & - \\
\hline 4 & MA & 16 & + & - & + & + & $\mathrm{II}_{\mathrm{B}}$ & + & + & - \\
\hline 5 & MA & 10 & + & + & + & + & $\mathrm{II}_{\mathrm{A}}$ & + & - & - \\
\hline 6 & MA & 10 & + & + & + & - & $\mathrm{II}_{\mathrm{A}}$ & + & + & - \\
\hline 7 & MA & 8 & + & + & + & + & $\mathrm{II}_{\mathrm{A}}$ & + & + & - \\
\hline 8 & $\mathrm{MM}$ & 10 & + & + & + & + & $\mathrm{II}_{\mathrm{A}}$ & + & - & - \\
\hline 9 & $\mathrm{MM}$ & 10 & + & + & + & + & $\mathrm{II}_{\mathrm{A}}$ & + & - & - \\
\hline 10 & MA & 16 & + & + & + & + & $\|_{B}$ & - & + & - \\
\hline 11 & $\mathrm{CA}$ & 9 & + & + & + & + & $\|_{\mathrm{A}}$ & + & - & - \\
\hline 12 & MA & 9 & + & - & + & + & $\mathrm{II}_{\mathrm{A}}$ & - & + & - \\
\hline 13 & $\mathrm{CA}$ & 8 & + & + & + & + & $\mathrm{II}_{\mathrm{A}}$ & + & - & - \\
\hline 14 & $\mathrm{CA}$ & 21 & + & + & + & - & III & + & + & - \\
\hline 15 & $\mathrm{CA}$ & 10 & + & + & + & + & $\|_{\mathrm{A}}$ & + & - & - \\
\hline 16 & $\mathrm{CA}$ & 13 & + & + & + & + & $\mathrm{II}_{\mathrm{A}}$ & + & - & - \\
\hline 17 & $\mathrm{CA}$ & 16 & + & + & + & + & $\|_{B}$ & + & + & - \\
\hline 18 & $\mathrm{CA}$ & 15 & + & + & + & + & $\mathrm{II}_{\mathrm{B}}$ & - & + & - \\
\hline 19 & $\mathrm{CA}$ & 11 & + & + & + & + & $\mathrm{II}_{\mathrm{A}}$ & + & - & - \\
\hline 20 & $\mathrm{CA}$ & 10 & + & + & + & + & $\|_{\mathrm{A}}$ & + & + & - \\
\hline 21 & $\mathrm{CA}$ & 8 & + & + & + & + & $\mathrm{II}_{\mathrm{A}}$ & + & - & - \\
\hline 22 & $\mathrm{CA}$ & 14 & + & + & + & + & $\|_{B}$ & + & + & - \\
\hline 23 & $\mathrm{CA}$ & 18 & + & + & + & + & III & + & + & - \\
\hline 24 & MA & 9 & + & + & + & - & $\mathrm{II}_{\mathrm{A}}$ & + & - & - \\
\hline
\end{tabular}

(+) Positivo para o parâmetro avaliado, (-) Negativo para o parâmetro avaliado.

${ }^{a}$ Classificação segundo Kenney e Doig (1986).

b Classificação de Hoffman et al. (2009).

Outro fato que explicaria o número elevado de fêmeas com endometrite micótica nesta pesquisa é que atualmente há uma maior exposição das éguas aos "fatores facilitadores" da colonização fúngica (vide Dascanio et al., 2001), como observado no histórico, anamnese e exame ginecológico de todas as éguas $(100 \%)$ em que esta foi diagnosticada (Tabela 2). Dentre estes "fatores" observou-se que o uso indiscriminado de antibióticos por via intrauterina, utilizado na tentativa de combater endometrites supostamente bacterianas, foi relevante para o desenvolvimento da endometrite fúngica (Brook ,1982; Alvarenga, 2008; Liu e Troedsson, 2008). Nesta pesquisa três das cinco éguas (números 1, 22 e 23, Tabela 2) haviam sido tratadas com antibióticos por via intrauterina antes do diagnóstico da endometrite fúngica. Durante este tipo de tratamento, ocorre um refluxo do medicamento para a vagina, eliminando bactérias como os Lactobacillus spp., essenciais na proteção do útero da égua por secretarem substâncias antifúngicas, alterando também a competição por nutrientes e o pH vaginal. $\mathrm{Na}$ ausência destas substâncias, criam-se melhores condições para sobrevivência e desenvolvimento do fungo, o qual é posteriormente carreado para o útero (Carter e Chengappa, 1995; Fraga et al., 2008).

Uma das éguas com endometrite micótica (Égua 6, Tabelas $1 \mathrm{e}$ 2) foi uma receptora de embriões e tinha em seu histórico uma perda embrionária precoce após inovulação de um embrião. Na tentativa de melhorar as chances de sobrevivência e manutenção do embrião nela inovulado, foram administrados $1500 \mathrm{mg}$ de progesterona de longa ação por via intramuscular, sendo este procedimento rotina em muitos dos programas de transferência de embriões (TE). Comprovadamente, a progesterona diminui a capacidade dos leucócitos em identificar, fagocitar e lisar agentes patogênicos pela ação do óxido nítrico (Troedsson, 2008) predispondo o útero a infecções fúngicas (Schauffler, 1972; Hinrichs et al., 1992; Dascanio, 2007). Além disso, como a cultura uterina não foi realizada após a perda embrionária, não se pode descartar o envolvimento fúngico neste processo (Blanchard e Filkins, 1992; Petrites-Murphy et al., 1996).

O animal 10 (Tabelas 1 e 2) havia sido adquirido em um leilão e por isso só havia o histórico a partir de sua compra, embora 
fosse possível saber, pelo seu registro genealógico, que era plurípara. Após sua chegada à propriedade, observaram-se ciclos irregulares pós-cobertura e no exame ginecológico má conformação vulvar e um deslocamento cranial do reto e parte da vulva, devido ao abdômen penduloso do animal. Esta alteração anatômica leva a uma maior predisposição a autocontaminação fecal (Card, 2005; Alvarenga, 2008; Bucca et al., 2008) como predisponente a endometrite fúngica. Neste sentido, todas as éguas apresentavam comprometimento em diferentes graus da conformação vulvar.

Outro fato a ser mencionado é que todos os animais (100\%) com endometrite fúngica pertenciam a propriedades muito tecnificadas, com acompanhamento permanente de médicosveterinários. Estes regularmente diagnosticavam e tratavam endometrites com antibióticos intrauterinos e numa das propriedades a TE foi amplamente utilizada, ou seja, havia frequente manipulação genital, o que facilitaria o carreamento mecânico do fungo para o útero (LeBlanc et al., 2007; Alvarenga, 2008).

Os fungos isolados do útero das éguas com endometrites e a descrição dos achados citológicos e histopatológicos encontramse na Tabela 2. Foram isoladas e identificadas quatro espécies de Candida, o que está em concordância com a literatura que destaca a participação deste gênero nas endometrites fúngicas (Zafracas, 1975; Abou-Gabal, 1977, Brook, 1982; Pugh et al., 1986 ; Plagemann et al., 1991; Dascanio et al., 2001; Amaral et al., 2008; Frontoso et al., 2008; Liu e Troedson, 2008), sendo que, do útero do animal 1 (Tabela 2) foram isoladas três espécies de Candida.

Os outros dois fungos restantes foram do gênero Trichosporon. Embora o envolvimento deste gênero de fungo nas endometrites em éguas já estar relatado na literatura (Freeman et al., 1986; Hinrichs et al., 1992; Dascanio et al., 2001), as espécies isoladas no presente estudo, T. capitatum e T. penicillatum, ainda não haviam sido descritas como agentes etiológicos de endometrites. Existem relatos do envolvimento destas espécies em complicações broncopulmonares (Looder e Van Rij, 1970) além de doenças granulomatosas em humanos (Fagundes Junior et al., 2008) e em aves (Gründer et al., 2005).

Em relação às infecções mistas, os exames bacteriológico e micológico foram positivos em duas éguas (Tabela 2). Quanto à associação fúngica e bacteriana, as registradas foram da $C$. guilliermondii, C. pseudotropicalis e C. tropicalis com a bactéria Bacillus sp., bactéria componente da microbiota da vagina de éguas (Fraga et al., 2008). Já a outra, formada por $C$. albicans com a bactéria $E$. coli já havia sido observada e provavelmente tem relação com a contaminação da vagina por fezes, pois os dois patógenos fazem parte da microbiota intestinal dos equinos. Normalmente a infecção inicial é causada pelo fungo, após a utilização de antibióticos por via intrauterina, o que leva a uma alteração ainda maior do microambiente vaginal, favorecendo a colonização por bactérias oportunistas (Frontoso et al., 2008).

No que diz respeito à reação tecidual causada pelo fungo, pôde-se constatar a presença de pelo menos dois neutrófilos/ dez campos da amostra da citologia endometrial, nas cinco éguas (100\%) em que os fungos foram isolados. Os processos inflamatórios foram classificados segundo Riddle et al. (2007) em moderados (Tabela 2). Nenhuma inflamação severa, como relatada em outros estudos (Freeman et al., 1986; Ball et al., 1988; Roszel e Freeman, 1988; Amaral et al., 2008) foi constatada. Justifica-se este fato à ausência de uma inflamação tipicamente aguda nos casos clínicos desta pesquisa e sim a uma inflamação crônica. Colabora para tal afirmação a presença de leucócitos mononucleares, principalmente linfócitos/plasmócitos típicas deste tipo de inflamação, em todas as amostras endometriais das éguas com endometrite micótica. A presença de linfócitos/ plasmócitos talvez seja um forte indicativo de endometrite com envolvimento fúngico, assim como observado por Mcgorum et al. (1993) em patologias pulmonares com a mesma etiologia em equinos.

Ao contrário de Causey (2007), que afirma que éguas com endometrite produzem mais muco, observou-se através da vaginoscopia e na citologia vaginal, a presença marcante deste apenas na égua que apresentava lesão na cérvix (Égua 23, Tabela 2). A cérvix é o órgão mais importante para a limpeza física do útero e seu mau funcionamento leva a menores contrações miometriais, prejudicando esta limpeza (Le Blanc, 2003; Causey, 2007; Bucca, 2008).

Constatou-se a presença de fungos no exame citológico de quatro das cinco éguas que apresentaram cultura positiva para fungos, confirmando ser este um método eficaz para detecção destes patógenos e de diagnosticar-se a endometrite fúngica, assim como propôs Alvarenga (2008).

O outro método utilizado para complementação diagnóstica da endometrite fúngica foi à biópsia endometrial que revelou as alterações inflamatórias teciduais causadas pelo fungo. As observadas nas éguas com exame micológico positivo nesta pesquisa (Tabela 2), estão de acordo com as relatadas por Zafracas (1975), Pugh et al. (1986a,b) e Freeman et al. (1986). Contudo, no presente trabalho não se observaram eosinófilos, nem inflamações tipicamente agudas, representadas por infiltrado maciço de neutrófilos e formação de microabscessos. Tal fato é justificado por serem endometrites de caráter crônico. Porém, na biópsia, foi possível constatar inflamações crônicas com uma reação aguda se sobrepondo, principalmente, em duas éguas (Éguas 22 e 23; Tabelas 1 e 2), provavelmente devido à contaminação recorrente do útero, causada pela manipulação excessiva do trato reprodutivo destes animais. Eigenheer-Moreira et al. (2007) observaram este mesmo tipo de inflamação em éguas repetidoras de cio utilizadas em programa de transferência de embriões.

Observou-se também que todas as éguas com endometrite fúngica apresentavam alterações endometriais degenerativas, sendo mais comuns as fibroses periglandulares $(100 \%$ das éguas), mas também se diagnosticou fibroses perivasculares em duas das éguas (40\%; Tabelas 1 e 2). Estudos anteriores (Cadario et al., 2002; Keller et al., 2006; Schaffler, 2007; Hoffman et al., 2009) propõem que endometrites persistentes e crônicas causam este tipo de reação devido à irritação constante do agente infeccioso no tecido uterino levando: (1) ao aumento da produção de citocinas fibrogênicas e hipóxia; (2) ao mau funcionamento das glândulas endometriais devido à diminuição dos sinais parácrinos entre suas células; (3) a diminuição da produção de muco e consequentemente a limpeza uterina e (4) a dificuldade de diapedese e fagocitose leucocitária.

A lifangectasia também foi um achado comum nestas fêmeas, mesmo em diestro, tanto na palpação transretal, quanto na biópsia endometrial, concordando com os achados de Riddle et 
Tabela 2: Histórico, anamnese, exame ginecológico, espécies isoladas e descrição da citologia e histopatologia endometrial das cinco éguas com endometrite fúngica

\begin{tabular}{|c|c|c|c|c|c|}
\hline Égua no & Histórico e anamnese & Exame Ginecológico & Cultura & Descrição da citologia vaginal & Descrição da histopatologia \\
\hline 1 & $\begin{array}{l}\text { Plurípara, vazia há duas es- } \\
\text { tações de monta, dificuldade } \\
\text { em emprenhar, diagnósticos } \\
\text { anteriores de endometrtites } \\
\text { persistentes, tratada pelo } \\
\text { menos duas vezes com antibi- } \\
\text { óticos (penicilina, gentamicina) } \\
\text { por via intrauterina (IU). }\end{array}$ & $\begin{array}{l}\text { Conformação razoável } \\
\text { de vulva (Índice Caslik IC } \\
=117,5 \text { ), útero com dimi- } \\
\text { nuição do tônus, cornos } \\
\text { assimétricos, parede do } \\
\text { corno direito espessada. }\end{array}$ & $\begin{array}{l}\text { Candida guilliermondii, } \\
\text { C. tropicalis, } \\
\text { C. pseudotropicalis } \\
\text { Bacillus sp }\end{array}$ & $\begin{array}{l}\text { Células endometriais normais; } \\
\text { dois neutrófilos/campo em } \\
10 \text { campos (inflamação mo- } \\
\text { derada) grande quantidade } \\
\text { de leucócitos mononucleares } \\
\text { (linfócitos); um histiófago com } \\
\text { leveduras fagocitadas em seu } \\
\text { interior; células leveduriformes } \\
\text { e pseudo-hifas. }\end{array}$ & $\begin{array}{l}\text { Epitélio luminal colunar baixo; } \\
\text { linfangectasia moderada difusa, } \\
\text { fibrose periglandular moderada; } \\
\text { glândulas dilatadas; infiltrado } \\
\text { inflamatório moderado e difuso, } \\
\text { formado principalmente por mono- } \\
\text { nucleares; presença de hemosi- } \\
\text { derófagos. }\end{array}$ \\
\hline 6 & $\begin{array}{l}\text { Plurípara, relatos anteriores } \\
\text { de diminuição do tônus uterino } \\
\text { no início da gestação e perda } \\
\text { embrionária. Receptora de } \\
\text { programa de transferência de } \\
\text { embriões, tratada com proges- } \\
\text { terona por via intramuscular } \\
\text { na última estação de monta. } \\
\text { Intensa manipulação do trato } \\
\text { reprodutivo. }\end{array}$ & $\begin{array}{l}\text { IC }=110,0 \text {. Lábios vulva- } \\
\text { res com fechamento irre- } \\
\text { gular por } 2 \mathrm{~cm} \text {, pequena } \\
\text { ferida na cérvix que por } \\
\text { sua vez é longa }(5,5 \mathrm{~cm} \\
\text { de comprimento e com } \\
\text { diâmetro aumentado } \\
\text { uns } 2,0 \mathrm{~cm}) \text {, útero com } \\
\text { diminuição do tônus. }\end{array}$ & Trichosporon capitatum & $\begin{array}{l}\text { Células endometriais normais; } \\
\text { dois neutrófilos/ campo em } \\
10 \text { campos (inflamação mo- } \\
\text { derada); presença de poucos } \\
\text { mononucleares; hifa septada. }\end{array}$ & $\begin{array}{l}\text { Epitélio colunar baixo; linfangecta- } \\
\text { sia discreta difusa; vasos conges- } \\
\text { tos; fibrose periglandular discreta; } \\
\text { fibrose perivascular moderada; } \\
\text { formação de ninhos glandulares } \\
\text { fibrosados ( } 1 \text { por campo de } 5,5 \\
\text { mm.), infiltrado inflamatório mode- } \\
\text { rado e difuso, formado principal- } \\
\text { mente por mononucleares. }\end{array}$ \\
\hline
\end{tabular}

Plurípara, adquirida vazia em leilão há 2 anos. Desde então permanece vazia, tendo sido coberta por diversas vezes na estação de monta do ano anterior. Ciclos irregulares.
Retração do reto e vulva no sentido cranial. Alteração da conformação da vulva, $(I C=115,0)$ Tônus uterino diminuído, útero penduloso e voltado para a cavidade abdominal, cistos endometriais palpáveis.

\begin{tabular}{|c|c|c|}
\hline Trichosporon penicillatum & $\begin{array}{l}\text { Células endometriais normais; } \\
\text { dois neutrófilos/campo em } 10 \\
\text { campos (inflamação modera- } \\
\text { da); poucos mononucleares } \\
\text { (linfócitos). }\end{array}$ & $\begin{array}{l}\text { Epitélio colunar baixo; linfangec- } \\
\text { tasia difusa a moderada; infiltrado } \\
\text { inflamatório discreto e difuso } \\
\text { formado principalmente por mo- } \\
\text { nonucleares, fibrose moderada de } \\
\text { ramos individuais das glândulas } \\
\text { endometriais, glândulas com } \\
\text { dilatações císticas. }\end{array}$ \\
\hline
\end{tabular}

Candida albicans

Células endometriais morfologicamente anormais; três neutrófilos/campo em $10 \mathrm{cam}$ pos (inflamação moderada): presença de mononucleares

Escherichia coli presença de mononucleares
(linfócitos e plasmócitos); presença de eosinófilos; células leveduriformes pseudo-hifas $e$ hifas septadas. -estratificado; linfangectasia difusa
Epitélio colunar baixo com áreas formadas por epitélio pseudoe moderada; pequenos focos hemorrágicos; vasos congestos; fibrose periglandular moderada e perivascular discreta; infiltrado inflamatório discreto difuso misto no estrato compacto; infiltrado inflamatório multifocal moderado constituído por neutrófilos e plasmócitos no estrato esponjoso.

Epitélio colunar alto com áreas de epitélio pseudo-estratificado; edema discreto difuso; glândulas com dilatações císticas; fibrose periglandular severa e perivascular moderada; ninhos glandulares fibrosados, três por campos de 5,5 $\mathrm{mm}$ por mais de quatro campos lineares; infiltrado inflamatório difuso moderado, constituído por neutrófilos e mononucleares com presença marcante de plasmócitos. nos anos anteriores e com amicacina há duas semanas. Ciclos irregulares.
Conformação de vulva ruim $(I C=115,2)$, cérvix
irregular, com desvio, aderências, estenosada e fibrosada. Presença de grumos e "debris" na cérvix e no fundo de saco vaginal. Útero com pequenas áreas de con- sistência firme (fibrose) paredes espessadas, trico. Pequena coleção palpável de líquido no corno esquerdo.

Células endometriais atípicas presença de muco em grande campo, em 10 campos na maioria degenerados (inflamação moderada); presença de mononucleares (plasm mes e pseudo-hifass.
GMS para a identificação de fungos em amostras endometriais, relataram que o primeiro é mais eficiente, principalmente na identificação de leveduras, fungos mais comuns nesta pesquisa. A explicação para isso é a maior afinidade do PAS a quitina e $\mathrm{N}$-acetil glicosamina, polissacarídios mais importantes na constituição da parede das leveduras. O GMS é específico somente para poucos constituintes químicos da parede destas

leveduras (Culling et al. 1985) sendo mais difícil identificá-las al. (2007) e Le Blanc (2008). A presença de edema endometrial compromete a drenagem de subprodutos do processo inflamatório (Malschitzky et al. 2007) e este leva à diminuição das contrações miometriais necessárias para limpeza uterina (Le Blanc et al. 2008). No entanto, ao contrário do que ocorreu na citologia, não foi possível identificar estruturas fúngicas nas amostras mesmo utilizando-se a coloração de GMS que facilitaria esta identificação. Amaral et al. (2007) quando utilizaram PAS e 
por esta técnica que pelo PAS. Além disso, Ball et al. (1988) e Nielsen (2005) afirmam que nas endometrites, a reação inflamatória é observada em todo útero, embora o agente infeccioso não esteja presente em toda a sua extensão.

Comparando o exame citológico com a biópsia, constatou-se que a citologia é capaz de demonstrar elementos fúngicos mais facilmente que as biópsias, embora os sinais inflamatórios sejam observados em ambos. Entretanto, a biópsia analisa a capacidade funcional do endométrio e lesões degenerativas conferindo melhores parâmetros para uma avaliação mais detalhada da vida reprodutiva deste animal.

Levando-se em consideração o quadro inflamatório, a funcionalidade e as lesões endometriais, concorda-se com Amaral et al. (2007) que os quadros clínicos considerados mais graves foram os das éguas com endometrites causadas por Candida albicans. Este fungo, da mesma forma que bactérias como E. coli, têm a capacidade de formar biofilmes, compostos de material polimérico extracelular que combinado com uma densa rede de leveduras, hifas e pseudohifas, aumentam a adesão às superfícies epiteliais dificultando a limpeza uterina. Os biofilmes também interferem nos mecanismos imunológicos de defesa uterina contribuindo com a capacidade de resistir à eliminação uterina (Alvarenga, 2008). Provavelmente este fato tenha contribuído para que os causadores da endometrite da Égua 22 (Tabela 2) tenham se infiltrado mais profundamente no endométrio, causando uma reação inflamatória no estrato esponjoso e lesionando algumas glândulas endometriais. $\mathrm{O}$ quadro clínico da Égua 23 também é bastante preocupante, uma vez que possui a cérvix fibrosada, fato também observado por Pugh et al. (1986a) e Blue (1987), em éguas com endometrite fúngica e apontado por Casey (2007) e Bucca et al. (2008) como incompatível com uma função reprodutiva normal.

Contudo, pode-se considerar como desfavorável o prognóstico reprodutivo de todas as éguas com endometrites fúngicas desta pesquisa pois podem ser classificadas como susceptíveis a endometrites persistentes, não conseguindo debelar a infecção endometrial devido às falhas em suas defesas uterinas. Logo estas se tornam crônicas como descrito por Fumuso et al. (2007). Deve-se lembrar que endometrites crônicas estão associadas a folículos anovulatórios (LeBlanc, 2008) e maior dificuldade de gestar. Além disso, as endometrites fúngicas são extremamente recidivantes (Alvarenga, 2008) e nenhuma

\section{Referências}

ABOU-GABAL, M.; HOGLE, R.M.; WEST, J.K. Pyometra in a mare caused by Candida rugosa. J. Am. Vet. Med. Assoc., v. 70, p. 177, 1977.

ALBIHIN, A.; BÄVERUD, V.; MAGNNUSSON, U. Uterine microbial susceptiibility in isolated bacteria from mares with fertility problems. Acta Vet. Scand., v. 44, p. 121-129, 2003.

ALVARENGA, M.A. Diagnóstico e tratamento de endometrite fúngica em éguas. In: IX CONFERÊNCIA ANUAL DA ABRAVEQ, 2008. São Paulo, Brasil. Anais... São Paulo. 2008, (CD Room).

AMARAL, M.G.; PIMENTEL, C.A.; MEIRELES, M.; FIALA, S. M.; SCHRAMM, R.; XAVIER, E.G.; MENDONÇA M. Endometrite eqüina. Fungos e bactérias. Arch. Zootec., v.216, v.875-884, 2007. das éguas com infecções fúngicas das pesquisas de Amaral et al. (2007) e Riddle et al. (2007) gestaram na estação de monta seguinte ao tratamento.

Le Blanc (2003) afirma ainda que éguas que apresentam fluido uterino acumulado decorrente de endometrites apresentam maior dificuldade de levar a gestação a termo. Isto ocorre por efeito direto do fluido no ambiente uterino, tornando-o incompatível com a sobrevivência do embrião ou ainda ocasionado pela liberação constante de prostaglandina $F_{2 a}$ devido à inflamação, levando à diminuição da progesterona circulante pela lise do corpo lúteo. Mais um agravante seria a idade das éguas em questão (acima de 10 anos) que levaria à diminuição da capacidade reprodutiva do animal, também por diminuição da capacidade de suporte uterino para o embrião uma vez que as estruturas endometriais envolvidas na síntese e secreção de nutrientes estão comprometidas (Casey, 2007; Eigenheer-Moreira et al., 2007). Por isso, mesmo após o tratamento adequado, dependendo da genética deste animal, deve-se encaminhá-lo a um programa de T.E., e mesmo neste, deve-se empregar técnicas de mínima contaminação quando da necessidade de manipulação do útero e uma única inseminação por ciclo. Deve-se também procurar diminuir o número de ciclos utilizados por estação nestes programas de TE, utilizando-se ciclos intercalados para coleta de embriões (Alvarenga, 2008).

\section{Conclusões}

A endometrite fúngica é uma importante enfermidade reprodutiva em éguas, mas devido ao diagnóstico complexo, não é identificada e, consequentemente, tratada a contento, ocasionando a cronificação da doença. A metodologia utilizada foi eficiente na identificação das endometrites fúngicas, ressaltando-se a importância para o cultivo adequado do fungo e a identificação das estruturas fúngicas nas lâminas de citologia endometrial. Os fungos isolados mais frequentemente foram do gênero Candida, porém também isolaram-se fungos do gênero Trichosporon. Embora a biópsia endometrial não tenha revelado estruturas fúngicas, foi bastante importante para demonstrar as principais lesões uterinas, todas com caráter crônico, que resultaram em um prognóstico reprodutivo desfavorável para todas as éguas acometidas pela enfermidade.

AYALA, M.J.; ORTIZ, F.N. Citologia e Ginecologia, Tomo 1: texto. Livraria Editora Artes Médicas, São Paulo, Brasil, 1978. 204 p.

BAIN, A.M. The role of infection in infertility in the thoroughbred mare. Vet. Rec., v. 78, p.168-173, 1966.

BALL, B.A.; SHIN, S.J.; PATTEN, V.H. Embryonic loss in pony mares, induced by intrauterine infusion of Candida parapsilosis. Theriogenology, v. 29, p. 835-847, 1988.

BLANCHARD, P.C.; FILKINS, M. Cryptococcal pneumonia and abortion in an equine fetus. J. Am. Vet. Med. Assoc., v. 201, p.1591-1592, 1992.

BLANCHARD, T.L.; VARNER, D.D.; SCHUMACHER, J. Manual of equine reproduction. Mosby, St Louis. 1998. 209 p.

BLUE, M.G. Mycotic endometrites in mares: Review and clinical observation. N. Z. Vet. J. v. 35, p. 181-183, 1987. 
BLUE, M.G. Mycotic invasion of mare's uterus. Vet. Rec. v. 113, p.131-132, 1983.

BROOK, D. Diagnosis of equine endometrial candidiasis by direct smear and successful treatment with amphotericin B and oxitetracycline. J. South Afr. Vet. Assoc. v. 53, p. 261-262, 1982.

BUCCA, S.; CARLI, A.; BUCKLEY, T.; DOLCI, D.; FOGARTY, U. The use of dexamethasone administered to mares at breeding time in the modulation of persistent mating induced endometritis. Theriogenology, v. 70, p.1093-1100, 2008.

CADARIO, M.E.; LOSINNO, L.; GIGUERE, S.; AGUILAR, J.; JACK, T.J.; MACPHERSON, M.; FITZPATRICK, C; UHL, E.W. Uterine expression of fibrogenic cytokines in the mare. Theriogenology, v. 58, p.449-452, 2002.

CARD, C. Post-breeding inflammation and endometrial cytology in mares. Theriogenology, v. 64, p. 580-588, 2005.

CARTER, G.R.; CHENGAPPA, M.M. Introduction to de fungi and fungous infeccion. In: CARTER, G.R.; CHENGAPPA, M.M; ROBERTS, G.H.C.; RIKIHISA, Y. (Eds), Essentials of Veterinary Microbiology. Philadelphia: Williams and Wilkins, 1995. p.251-256

CAUSEY, R.C. Mucus and the mare: How little we know. Theriogenology, v. 68, p. 386-394, 2007.

COLLINS, S.M. Study of incidence of cervical uterine infections in Thoroughbred mares in Ireland. Vet. Rec., v. 66, p. 673-676, 1964.

CULLING, C.F.A.; ALLISON, R.T.; BARR, W.T. Cellular pathology technique. $4^{\text {th }}$ ed., Vancouver: Butterworth, 1985. p. 219-222.

DASCANIO, J.J. Treatment of fungal endometritis. In: SAMPER, J.C.; PYCOCK, J.F.; Mc KINNON A.O. (Eds). Current Therapy in Equine Reproduction. StLouis:Saunders Elsevier, . 2007.p.116-120.

DASCANIO, J.J.; SCHWEIZER, C.; LEY, W.B. Equine fungal endometritis. Equine Vet. Educ., v. 13, p. 324-329, 2001.

EIGENHEER-MOREIRA, J.F.; FERNANDES, F.T.; QUEIROZ, F.J.R.; PINHO, T.G.; FERREIRA, A.M.R. Estudo comparativo de éguas repetidoras ou não de cio através da avaliação histológica do endométrio e das concentrações plasmáticas de progesterona. Pesq. Vet. Bras., v. 27, p. 506-512, 2007.

FAGUNDES JÚNIOR, A.A.P.; CARVALHO, R.T.; FOCACCIA, R; FERNANDEZ, J.G. Emergência de infecção por Trichosporon Asahii em pacientes portadores de insuficiência cardíaca em Unidade de Terapia Intensiva Cardiológica: relato de caso e revisão da literatura. Rev. Bras. Terapia. Interna, v. 20, p. 106109, 2008.

FERRIS, R.A., DERN, K.; VEIR, J.K.; HEWLEY, J.R.; LAPPIN, M.R.; McCUE, P.N. Development of a broad-range quantitative polymerase chain reaction assay to detect and identify fungal DNA in equine endometrial samples. Am. J. Vet. Res, v. 74, p. 161-165, 2013.

FRAGA, M.; PERELMUTER, K.; DELUCCHI, L.; CIDADE, E.; ZUNINO P. Vaginal lactic acid bacteria in the mare: evaluation of the probiotic potential of native Lactobacillus spp. and Enterococcus spp. Strains. Antonie Van Leeuwenhoek, v. 93, p. 71-78, 2008.

FREEMAN, K.P.; ROSZEL, J.F.; SCHULER, S.H. Micotyc infeccions of the equine uterus. Equine Pract., v. 8, p. 34-42, 1986.

FRONTOSO, R.; DE CARLO, E.; PASOLINI, M.P.; VAN DER MEULEN, K.; PAGNINI, U.; IOVANE, G; DE MARTINO, L. Retrospective study of bacterial isolates and their antimicrobial susceptibilities in equine uteri during fertility problems. Res. Vet. Sci., v. 84, p. 1-6, 2008.
FUMUSO, E.A.; AGUILAR, J.; GIGUĖRE, S.; RIVULGO, M.; WADE, J.; ROGAN, D. Immune parameters in mares resistant and susceptible to persistent post-breeding endometritis: Effects of immunomodulation. Vet. Immunol. Immunopathol., v. 1, p. 830-39, 2007.

GHASEMZADEH-NAVA, H.; GHASEMI, F.; TAJIK, P. A review of mare endometritis in Iran. J. Equine Vet Sci., v. 24, p. 188-191, 2004.

GRÜNDER, S; MAYSER, P.; REDMANN, T.; KALETA, E.F. Mycological examinations on the fungal flora of the chicken comb. Mycoses, v.48, p. 114-119. 2005.

HINRICHS, K.; SPENSELEY, M.S.; MCDONOUG, P.L. Evaluation of progesterone treatment to create a model for equine endometritis. Equine Vet. J., v. 23, p. 456-461. 1992.

HOFFMANN, C.; ELLENBERGE, C.; MATTOS, R.C.; AUPPERLE, H.; DHEIN, S.; STIEF, B.; SCHOON, H.A. The equine endometrosis: New insights into the pathogenesis. Anim. Reprod. Sci., v. 111, p. 261-278, 2009.

JACOB, J.C.F.; JESUS, V.L.T.; BARBOSA, H.P.; ZIMMERMAN, M.F.; SILVA, A.G.; MELO C.M.. Susceptibilidade antimicrobiana de swab uterino e da fossa clitoriana de éguas com subfertilidade. Rev. Univ. Rural, Série Ciência da Vida, v. 22, p. 109-114 (Suplemento).

JITSURONG, S.; KIAMSIRI, S.; PATTARARANGRONG, N. New milk medium for germ tube and chlamydoconidia production by Candida albicans. Mycophatology, v. 23, p. 95-98. 1993.

KELLER, A.; NEVES, A.P.; AUPPERLE, H.; STEIGER, K.B.; GARBADE, P.; SCHOON, H.-A.; KLUG, E.; MATTOS, R.C. Repetitive experimental bacterial infections do not affect the degree of uterine degeneration in the mare. Anim. Reprod. Sci., v. 94, p. 276-279, 2006.

KENNEY, R.M.; DOIG, P.A. Equine endometrial biopsy. In: MORROW, D.A. (Ed.), Current Therapy in Theriogenology. Philadelphia : W.B. Saunders, 1986. p.723-729.

KENNEY, R.M. Ciclic and pathologic changes of the mare endometrium as detected by biopsy, with a note on early embrionic death. J. Am. Vet. Med. Assoc., v. 172, p. 241-262, 1978.

LACAZ, C.S.; PORTO, E.; MARTINS, J.E.C. Micologia Médica: Fungos actinomicetos e algas de interesse médico. 7: ed. São Paulo: Sarvier, 1984. 479 p.

LANGONI, H. Abortos infecciosos das éguas. In: XI CONGR. BRAS. REPROD. ANIM., 1995. Belo Horizonte, Minas Gerais, Anais... Belo Horizonte, p. 80-88. 1995.

LANGONI, H.; ALVARENGA, F.O.; PAPA, F.O.; LUCHEIS, S.B.; SAKAMOTO, C.; LISTONI F.J.P.. Participação de bactérias aeróbicas, microaerófilas e anaeróbicas na endometrite eqüina. Rev. Bras. Reprod. Anim., v. 23, p. 44-51, 1999.

LEBLANC, M.M. Persistent mating induced endometritis. In: ROBINSON, N.E. (Ed.). Current Therapy in Equine Medicine, $5^{\text {th }}$ ed.., Philadelphia : W.B. Saunders, 2003. p. 234-237.

LEBLANC, M.M.; MAGSIG, J.; STROMBERG, A.J. Use of a lowvolume uterine flush for diagnosing endometrites in chronically infertile mares. Theriogenology, v. 68, p. 403-412, 2007.

LEBLANC, M.M.. When to refer an infertile mare to a theriogenologist. Theriogenology, v. 70, p. 421-429, 2008.

LEY, W.B. Reprodução. In: SAVAGE, C.J. (Ed.). Segredos em Medicina de Eqüinos. Porto Alegre : Art Med, 2001. p. 265-303.

LIU, K.M.; TROEDSSON, M.H.T. The diagnosis and treatment of endometritis in the mare: Yesterday and today. Theriogenology, v. 70 , p. $415-420,2008$ 
LOODER, J.; VAN RIJ, K.N.J. The Yeasts: A taxonomic study. Holland: Holland Nortt, 1970.1350 p.

MALSCHITZKY, E.; GREGORY, R.M.; JOBIM, M.I.M.; MATTOS R.C. Endometrite na égua, novos conceitos. Rev. Bras. Reprod. Anim., v. 31, p.17-26, 2007.

MATTOS, R.C.; MALSCHITZKY, E.; JOBIM, M.I.M. Endometrite na égua. Rev. Bras. Reprod. Anim., v. 27, p.150-157, 2003.

MCGINNIS, M.R. Yeast identification. In: MCGINNIS, M.R. (Ed.). Laboratory Handbook of Medical Mycology. London : Academic Press. 1980. p.37-411.

MCGORUM, B.C.; DIXON, P.M.; HALLIWELL, R.E.W. Phenotypic analysis of peripheral blood and bronchoalveolar lavage fluid lymphocytes in control and chronic obstructive pulmonary disease affected horses, before and after 'natural (hay and straw) challenges. Vet. Immunol. Immunopatol. v. 36, p. 207-22,. 1993.

MURRAY, P.R.; BARON, E.J.; PFALLER, M.A.; TENOVER, F.C.; YOLKEN, R.H. Manual of Clinical Microbiology. $7^{\text {th }}$ ed. Washington, DC.: American Society for Microbiology, $1700 \mathrm{p}$. 1999.

NICO, A.F.; GOUVEA, T.V.D.; COSTA, R.O. Candidíase vulvovaginal recorrente: uma contribuição ao diagnóstico. J. Bras. Doen. Sex. Trans., v. 6, p. 33-41, 1994.

NIELSEN, J.M. Endometritis in the mare: A diagnostic study comparing cultures from swab and biopsy. Theriogenology, v. 64, p.510-518, 2005

PETRITES-MURPHY, M.B.; ROBBINS, L.A.; DONAHUE, J.M.; SMITH, B. Equine cryptococcal endometritis and placentitis with neonatal cryptococcal pneumonia. J. Vet. Diagn. Invest., v. 8, p. 383-386, 1996.
PLAGEMANN, O.; WEBER, A.; KOEEPPEL, P. Chronische rezidivierende Endometritis bei einer Warmblutstute. Prakt. Tierarzt, v. 72, p. 603-605, 1996.

PUGH, D.G.; KLOPPE, L.H.; SIMPSON, R.B. Fungal endometrites in mares. Compend. Cont. Educ. v. 8, p. 173-181, 1986a.

PUGH, D.G.; MARTIN, M.T.; SHULL, J.W.; BOWEN J.M. Endometrial candidiasis in five mares. J. Equine Vet. Sci., v. 6, p. 40-43, $1986^{\mathrm{b}}$.

RIDDLE, W.T.; LEBLANC, M.M.; STROMBERG, A.J.

Relationships between uterine culture, cytology and pregnancy rates in a Thoroughbred practice. Theriogenology, v. 68, p. 395402, 2007.

ROSZEL, J.F.; FREEMAN, K.P. Equine endometrial citology. In: CAMP S.D.V. (Ed.), Vet. Clin. North Am., Equine Pract., Philadelphia : W.B. Saunders, v. 4, p. 247-262. 1988.

SCHAUFFLER, A.F. Maduromycotic mycetoma in an aged mare. J. Am. Vet. Med. Assoc., v. 160, p. 998-1000, 1972.

SCHLAFER, D.H. Equine endometrial biopsy: Enhancement of clinical value by more extensive histopathology and application of new diagnostic techniques? Theriogenology, v. 68, p. 413-422, 2007.

SPEIRS, V.C. Exame Clínico dos Equinos. Porto Alegre : Artmed, 1999. $366 \mathrm{p}$.

TROEDSSON, M.H.T. Problems after breeding. J. Equine Vet. Sci., v. 28, p. 635-639. 2008.

ZAFRACAS, A.M. Candida infection of the genital tract in thoroughbred mares. J. Reprod. Fertil., v. 23, p. 349-351, 1975. 